\title{
Exploring learners' Acceptance and Attitude towards Mobile Assisted Language Learning (MALL)
}

\author{
Tengku Nazatul Shima Tengku Paris ${ }^{1}$, Nurma Abdul Manap1, Hafiza Abas², Lo Mun Ling ${ }^{3}$ \\ 1 Universiti Teknologi MARA Pahang, Raub Campus, 27600, Raub, Pahang, Malaysia \\ ${ }^{2}$ Advanced Informatics Department, Razak Faculty of Technology and Informatics, Universiti Teknologi Malaysia, Kuala Lumpur, \\ ${ }^{3}$ Lo \& Lo Educational Consultancy Ltd., Hong Kong. \\ tnshima@uitm.edu.my, nurma@uitm.edu.my, hafiza.kl@utm.my, munling.lo@gmail.com: \\ Tel: 0199515668
}

\begin{abstract}
Two main reasons contributing to the lack of mastery in English grammar by students are their apprehension towards the subject and their difficulty understanding tenses. To alleviate the fear and trigger learners' interest in learning grammar, an interactive digital board game was designed via MALL targeted at TESL students. This paper aims to explore these students' perceptions of the game. The game uses the Theory of Variation as a theoretical basis that acknowledges that discernment is a function of variation. A questionnaire and interviews were administered to the students. The findings show that the game helps enhance grammar learning.
\end{abstract}

Keywords: Digital board game, Grammar, Mobile Assisted Language Learning, Variation theory

eISSN: 2398-4287@ 2021. The Authors. Published for AMER ABRA cE-Bs by e-International Publishing House, Ltd., UK. This is an open access article under the CC BYNC-ND license (http://creativecommons.org/licenses/by-nc-nd/4.0). Peer-review under responsibility of AMER (Association of Malaysian Environment-Behaviour Researchers), ABRA (Association of Behavioural Researchers on Asians/Africans/Arabians) and CE-Bs (Centre for Environment-Behaviour Studies), Faculty of Architecture, Planning \& Surveying, Universiti Teknologi MARA, Malaysia.

DOI: https://doi.org/10.21834/ebpj.v6i16.2734

\subsection{Introduction}

The study is a continuation of the researchers' previous study on the use of the digital board game "Throw Back Time" (TBT) via Mobile Assisted Language Learning (MALL). The previous study highlights on the results from the pre and post-test scores of grammar test after the respondents were given treatment on TBT via MALL. The current study, however, deals with students' perceptions on the use of TBT via MALL in learning grammar.

Knowledge of grammar needs to be emphasized as it is a crucial language component leading to proficiency. Mastery of grammar will result in better comprehension that could lead to better language learning (Rozina et al., 2017). Some of the problems that learners have to confront in English grammar are the fear that students have in grammar subject and the adversity in comprehending grammar tenses (Fitori, 2019). When students' foundation of grammar is shaky, they face problems using the language accurately and proficiently. The issues are due to students' apprehension in learning the metalanguage aspects, i.e., grammar rules and complicated vocabulary (Ediger, 2016). To enhance the learning of grammar, teachers need to expose learners to how grammar works through different grammatical structures (Diane Larsen-Freeman, 2015). To ease the anxiety and stimulate passion in grammar, educators have to integrate effective teaching with grammar (Brian, 2016).

Over the years, great strides have been made in analysing the benefits of computer-based and network-based software in the teaching and learning of language (Franciosi, 2017). However, the most important issue is how attainable and useful is the technology

eISSN: 2398-4287@ 2021. The Authors. Published for AMER ABRA CE-Bs by e-International Publishing House, Ltd., UK. This is an open access article under the CC BYNC-ND license (http://creativecommons.org/licenses/by-nc-nd/4.0/). Peer-review under responsibility of AMER (Association of Malaysian Environment-Behaviour Researchers), ABRA (Association of Behavioural Researchers on Asians/Africans/Arabians) and cE-Bs (Centre for Environment-Behaviour Studies), Faculty of Architecture, Planning \& Surveying, Universiti Teknologi MARA, Malaysia.

DOI: https://doi.org/10.21834/ebpj.v6i16.2734 
that would permit the teaching and learning to spread beyond the educational setting. One technology-based device that is useful and of vital importance to the students is the mobile phone. Ahn, Soo Kyung (2018) stated that smartphones have become a required appliance for Mobile Assisted Language Learning (MALL). Therefore, mobile phone can be an attainable tool for teaching and learning. The study aims to use MALL to teach grammar tenses and aspects (Simple Present, Simple Past, Present Continuous, and Past Continuous). It investigates learners' perceptions of using an interactive digital board game called Throw Back Time (TBT) via MALL in learning grammar.

\subsection{Literature Review}

\section{Technology Acceptance Model (TAM)}

Technology Acceptance Model (TAM) by Davis (1989) constitutes the theoretical foundation of this study. TAM is the most favourable theoretical framework in defining user acceptance of information technology (Kang, 2014) and mobile applications (Yeh, 2014). Two aspects, perceived usefulness (PU) and perceived ease of use (PEOU), are essential in adopting a technology. Perceived usefulness means "the degree to which a person believes that using a particular system would enhance his or her job performance" (Davis, 1989, p. 986). It has to do with an individual's perceptions of how technology will unmistakably affect one's ability towards better outcomes. Individuals will be optimistic that they will accomplish more with the use of technology. Perceived ease of use is defined as "the degree to which a person believes that using a particular system would be free of effort" (Davis, 1989, p. 984). It affects an individual's behaviour in utilizing technology. Perceived ease of use will affect behaviour and perceived usefulness. This theory was used to investigate and assess students' perceptions of TBT via MALL in learning grammar tenses in terms of perceived usefulness (PU) and perceived ease of use (PEOU).

\section{MALL}

The Mobile Assisted Language Learning (MALL), which is the subdivision of Mobile learning and CALL has made its way into the language classroom as it provides extensive learning benefits (Nikolopoulou, 2020). MALL brings technology into the classroom that turns lessons to be more effective and intriguing through the support of handheld mobile devices. The first handheld device to be used in MALL was through the Personal Digital Assistant (PDA) to assist learners with several tasks, including enhancing language learning (Mcquillan, 2006), testing incidental vocabulary (Song \& Fox, 2008), and personalizing the English vocabulary (Stockwell, 2007). As technology improved, the PDA was replaced by the iPod with its audio features as an enhancement to support language learning (Mcquillan, 2006), reading (Bomar, 2006), comprehension (Borgia, 2009), and listening skill (Kessler, 2010). Further improvement to learning was accelerated through web-based applications. The first web-based applications through the use of mobile phones were tutorial-based, aiming to strengthen vocabulary and grammar (Stockwell, 2007), reading (Huang \& Lin, 2011), and listening comprehension (Nah, 2011). Since then, the advancement in multimedia features from mobile phones under (MALL) has enabled transformation in learning for 21 st-century language learners based on its different features.

\section{Students' Perceptions on the Advantages of MALL}

It is vital to promote a relaxed and safe learning environment, especially when learners fear certain subjects, for instance, grammar. Some of the benefits of MALL include:

- Learners believe that they are subconsciously able to learn something under less pressure (Nikolopoulou, 2020). Once they notice that an application improves their grades, they will use and benefit from it (Davis, 1989).

- Learners perceive an approach is right, and it would be used as a practical after-class activity (Thomas \& Munoz, 2016; Yen et al., 2016). A supportive learning environment can make a big difference in the classroom environment in improving the learners' self-esteem and pursuing their goals.

- Learners can simultaneously participate in various learning activities, can receive course information, notes, and exercises almost instantly (Zou \& Li, 2015).

Therefore, MALL acts as a negotiator that provides personalized learning and promotes active learning. Active Learning can be combined with group work for maximum benefits. Learners acknowledge the excitement of working together using MALL as it leads to positive outcomes. Working together enables learners to support each other in completing activities and allows for more social interaction. This is in line with (Zamani-Miandashti \& Ataei, 2015) that the positive reflections on working together help learners to prosper. When the activities are well-planned and effectively managed, learners will be more engaged and work on reaching the learning objectives. Working together also involves risk-taking, where learners work as a team, share ideas, and make essential decisions to prepare them for the future.

\subsection{Methodology}

The research entailed the use of quantitative and qualitative measures. The sample population for this research was selected based on a purposive sampling of 48 Teaching English as a Second Language (TESL) Foundation Programme students of Universiti Teknologi MARA (UiTM) Dengkil Campus. To examine the students' perceptions on the benefits of using the digital board game via MALL, a questionnaire from Ducey (2013) was adopted to evaluate MALL's perceived usefulness and perceived ease of use with some changes made to suit the study. A 5-point-Likert Scale was used which focuses on Technology Acceptance Model (TAM) elements that include: 
1. Perceived Usefulness (PU) - to examine whether TBT via MALL helps learn grammar.

2. Perceived Ease of Use (PEOU) - to see whether TBT via MALL is easy to use.

3. Attitude $(A)$ - to check whether players accept TBT via MALL.

4. Behaviour to use (BI) - to examine whether players would continue using digital games via MALL in the future.

Eleven items used are run on the reliability statistics (Cronbach's Alpha) and SPSS 22 to check their internal reliability.

Besides the questionnaire, a semi-structured interview was also carried out. Standardized, open-ended questions were used with all the respondents in the session. The objective is to facilitate data analysis and comparison among the respondents. Before the interview, a field test was done by one ESL expert to check on the quality of the interview questions concerning the research question.

\section{TBT}

The digital board game is called "Throw Back Time" (TBT). The students will be trapped in different times reflected in the various English grammatical tenses such as the present, present continuous, past, or past continuous tense when playing the game. The game is developed using unity version 5.4 (2016) and then was upgraded to version 5.5 (2017). The concept of playing the digital board game is similar to playing the "Monopoly" game. The difference is that the "Monopoly" game involves buying and selling assets, whereas TBT involves verb formation. Before playing the game, players have to click on the 'practice' button to learn the basic aspects of grammar tenses and aspects. The game's design was based on a well-established, tested, and practiced learning theory, the variation theory (Lo, 2012). According to this theory, learning is a function of discernment, and discernment is a function of variation. To discern a certain aspect, that aspect must vary against an unchanging background of other aspects. Each learning object has many aspects. Each aspect must first be discerned separately through patterns of variation such as contrast, separation, or generalization, followed by the simultaneous variation of all aspects resulting in fusion (Lo, 2012). For example, in the game, each of the critical aspects (tenses) are treated separately with patterns of variation at first to help students discern them. These are integrated into steps (fusion) to help students see all the aspects together. Before students start playing the game, they have to click on the 'practice' button, where there will be notes, tables, and quizzes on each grammatical tense. The notes are in the form of a formula. It is used as a part of language learning strategy to help learners cultivate language competence as it permits learners to incarnate the learning development (Embi \& Amin, 2010). The formula will help students to remember the uses and functions of each tense easily. Once the students are confident about their progress on each grammar tense and aspect they can start playing the game by retreating from the 'practice' menu and clicking on the 'board game' button. There are 664 sets of questions arranged into six different types of questions in the game's quiz.

\subsection{Findings and Discussion}

This section presents the results from the questionnaire Using TAM.

\section{Perceived Ease of Use (PEOU)}

The findings show that $91.5 \%$ of the respondents strongly agree and agree that TBT via MALL is easy to use, and only $2.1 \%$ disagree with the statement. $100 \%$ strongly that it is easy to become skilful in using TBT via MALL. Besides, $91.5 \%$ of the respondents strongly agree and agree that learning how to use TBT via MALL is easy, only $2.1 \%$ disagree.

\section{Perceived Usefulness (PU)}

$100 \%$ of respondents strongly agree that TBT via MALL helps to improve grammar knowledge. Also, $85.1 \%$ of the respondents strongly agree that TBT via MALL helps them remember grammar rules.

\section{Attitude (AT)}

In addition, 95.8. \% of the respondents strongly agree and agree that Throwback Time (digital game) via MALL is an excellent idea to learn grammar, and only $4.3 \%$ remained neutral to the statement. A total of $97.8 \%$ of the respondents strongly agree and agree that Throwback Time (digital game) via MALL is a wise idea to learn grammar, and only $2.1 \%$ remained neutral. Apart from that, $78.8 \%$ of the respondents strongly agree and agree that they are positive towards TBT via MALL, while $21.3 \%$ remained neutral.

\section{Behavioral Intention (BI)}

A total of $91.5 \%$ of the participants intend to use MALL in various learning activities in the future, and the other $8.5 \%$ was neutral to the statement. A total of $68 \%$ strongly agree and agree to use MALL frequently, while $31.9 \%$ remained neutral. Lastly, $59.6 \%$ of the respondents intend to be a heavy MALL user, while the other remaining $40.4 \%$ was neutral to the statement.

Table 1 Students' perceptions on TBT via MALL

\begin{tabular}{|c|c|c|c|c|}
\hline No. & Statements & $\begin{array}{l}\text { Strongly } \\
\text { Agree } \\
(\%)\end{array}$ & $\begin{array}{l}\text { Neutral } \\
(\%)\end{array}$ & $\begin{array}{l}\text { Disagree } \\
(\%)\end{array}$ \\
\hline 1 & MALL is easy to use & 91.5 & 6.4 & 2.1 \\
\hline 2 & Easy to become skillful & 100 & & \\
\hline 3 & Learning how to use MALL is easy. & 91.5 & 6.4 & 2.1 \\
\hline 4 & MALL helps to improve grammar & 100 & & \\
\hline 5 & MALL helps to remember grammar & 85.1 & 14.9 & \\
\hline 6 & TBT via MALL is a good idea & 95.8 & 4.3 & \\
\hline
\end{tabular}


$7 \quad$ TBT via MALL is a wise idea

$8 \quad$ I am positive towards TBT via MALL

$9 \quad$ I intend to use MALL in various activities

$10 \quad$ I intend to use MALL frequently

$11 \quad$ intend to be a heavy user of MALL

$\begin{array}{ll}97.8 & 2.1 \\ 78.8 & 21.3 \\ 91.5 & 8.5 \\ 68 & 31.9 \\ 59.6 & 40.4\end{array}$

The findings from Perceived Ease of Use (PEOU) revealed that learners acknowledged the use of TBT via MALL mainly because they could use it easily and could easily become skilful in using it. This shows that the usability enhancement that the researcher made after seeing the flaws in the pilot test had benefitted the learners. The researcher had improvised the navigation element, userfriendliness system, and usability aspect after the pilot test. Hence, a user-friendly game could ease and facilitate learning as it is easy to use.

In terms of Perceived Usefulness (PU), Learners could also see the learning benefits from using the game based on their performance in the post-test (from the researcher's previous study). The results are in accordance with a previous study by Davis (1989), which claims that when students notice that an application will make a difference in their grades, they will see the application as beneficial and want to use it and benefit from it. The positive attitude represented their optimistic behaviour in using TBT via mobile technology. The results were also in line with a previous study by Franciosi (2017) that believe that learners' accomplishment depends on their recognition and value towards the particular activity given to them compared to other choices. The positive attitude was in line with the researcher's aim to transform the game into an enjoyable learning experience where the learners take control of their own learning process. The digital game is one of the suggestions to the tools that teachers can add to make grammar teaching interesting (Nikolopoulou, 2020). Interesting and competitive games allow learners to concentrate and try their best to win and simultaneously help them retain language input subconsciously. The results are supported by (Thomas \& Munoz, 2016; Yen et al., 2016) prove that using the digital game via MALL can lead to better learning improvement. Therefore, it is essential for teachers to design enjoyable as well as meaningful games that will lead to positive learning outcomes.

The following section describes the interview findings on TBT Via MALL's advantages, which offers learning benefits through constant practice, effective feedback function, fun learning experience, and a unique and useful application.

We believe that learning will not take place by itself even when exposed to the teaching materials. In MALL, teacher intervention is not available, therefore the game must be designed in such a way as to maximize learning in such a situation. Since the items were designed guided by variation theory, we are interested in finding out how the theory has contributed to learning. Two questions (4 and 5 ) on the questionnaire are related directly to grammar learning; they both scored very highly ( $100 \%$ and $85.1 \%)$. The interviews, on the other hand, revealed how the game helped them achieve learning. Participants claimed that they could 'compare and contrast' the usage of the tenses and aspect with the use of time markers.' One group claimed that "having more than one option in the answer part reminded us what the different verbs are for". Some commented that 'The options given lead us to the correct answers". Several other groups reported that "we know and remember what we do wrong and will not repeat the same mistakes." They were also adamant that the discernment of the critical elements will enhance their understanding of grammar. They agreed that when the tenses are mixed up, they learned different kinds of tenses quickly. All these reflected on the success of using the pattern of variation 'contrast' in the design. The usefulness of using the patterns of generalization and fusion is also reflected in the following: participants told us that they 'realized that different tenses and aspects convey different meanings. They further reported that "time phrases" did not always help them find the appropriate answers to the questions. Therefore, another method like checking the contextual clues was also necessary to discern the meaning. They managed to generalize the use of textual meaning to further discern the tenses and aspect. Other than that, they were more alert on the arrangement of "subject verb object." To make sure that the subjects of each tense and aspect agree with the object, they had to consider the singular and plural items. They felt that they did not take the element seriously before being exposed to the game. These are all in line with variation theory, which stresses that variation helps one discern what has been taken for granted.

Participants also welcomed the explanations or reasons initiated in the game. The explanations or reasons helped them learn the connections among the tenses and aspect in a more precise manner. Four of the groups claimed that "the notes in the explanations are concise and straight forward, we can remember the dos and don'ts of grammar elements. They believed they learned a lot from the explanations given that helped enhance their understanding of the critical elements better. Some groups claimed that "the explanations are beneficial as they come right after making the mistakes, the explanations explain what is right and wrong." They felt that the clarification in the explanation given helped enhance their grammar and their writing and speaking skills. By providing feedback, learners are more at ease as the game is fun and enjoyable.

Moreover, they reported that they were learning in a fun way. One group stated that "as we play, we learn something without realizing it." "We learn to look for clues; we learn the structure of different grammar elements and the specific usage of each tense and aspect." The other group added that "The game makes us independent learners. It all depends on us. If we want to be better, we have to play the game every day". They also added that they were subconsciously able to learn something while having fun in the activity. The positive emotion is in line with the researcher's aim to transform the game as an autonomous learning experience where the learners enjoyably control their learning process.

Several students claimed that using the game via MALL provided them with continuous practice to grammar exercise. "While other friends of mine are panicking and busy reading grammar notes for test 1, we can just relax; we know we will get a lot of input by just playing the game". They believed that the application involved less effort, and they were able to use it anywhere and anytime that they preferred to prepare for their test. Consequently, the approach engaged the students in learning constantly even when they were not under their teachers' supervision in the classroom.

The participants were also in favor of the game application. All of the groups agreed that "The game application is good." One way 
to sustain the novelty value is to develop stages of different difficulty levels that will sustain learners' interest in accomplishing their learning activities. Above all, they acknowledged the experience they received to see how grammar tenses and aspect work, discover answers to their uncertainties and discern the new grammar structures through plenty of drills.

The study has supported the Education Blueprint policy on the use of technology in the teaching and learning by adding to the pool of knowledge on the value of MALL. The positive results from the use of TBT via MALL can be an example of a learning tool to draw learners closer to grammar and to take away their fear towards grammar. The use of games that are governed by solid pedagogic principles can complement traditional face to face teaching method (Nikolopoulou, 2020). Teachers' burden of providing the technicalities of grammar knowledge can somewhat be eased by technology. Instead, teachers can focus on providing the necessary scaffolding to slow learners who demand personal coaching and attention. The findings from this study show how much learners are open to creative and innovative teaching. Their favourable accounts towards TBT game via MALL further emphasize the need for effective teaching strategy for a challenging subject, for instance, grammar. Learners' excitement to technology opens a new direction for teachers to utilize innovative techniques into the classroom. The findings also reveal the importance of catering to learners' learning diversity, learning flexibility, and innovative teaching techniques to create a successful learning environment. However, as the researcher was the one who interviewed the participants, there might have been a certain amount of inhibition from the learners when they shared their views and perceptions on the game. Future research can look into a game application that can correct students' sentences. It will be an engaging interactive game that can generate a two-way interaction between the player and the application.

\section{Acknowledgements}

Our most profound appreciation goes to TESL Foundation students of UiTM Dengkil to participate in the pilot study.

\section{Paper Contribution to Related Field of Study}

Educational / Learning Environment

\section{References}

Ahn, Soo Kyung. Alliant International University, ProQuest Dissertations Publishing, 2018. 10794038.

Bomar, L. (2006). iPods as reading tools. Principal, 85(5), 52-53.

Borgia, L. (2009). Enhanced vocabulary podcasts implementation in fifth grade classrooms. Reading Improvement, 46(4), 263-272.

Brian, G. (2016). Teacher knowledge of grammar in the primary school. ProQuest Dissertations and Theses, (October).

Davis, F. D. (1989). Perceived usefulness, perceived ease of use and user acceptance of information technology. MIS Quarterly, 13(3), 319-340.

Ducey, A. J. (2013). Predicting Tablet Computer Use: An Extended Technology Acceptance Model. Graduate Theses and Dissertations, Graduate t(January), 1-97.

Ediger, M. (2016). Studying Grammar in the Technological Age. Reading Improvement, 49(2), 72-73. Retrieved from http://libproxy.albany.edu/login?url=http://search.ebscohost.com/login.aspx?direct=true\&db=a9h\&AN=87775630\&site=ehost-live

Embi, M. A., \& Amin, M. Z. M. (2010). Strategies for successful English Language Learning (SELL). Karisma Publications Sdn. Bhd. Shah Alam.

Franciosi, S. J. (2017). The effect of computer game-based learning on vocabulary transferability. Educational Technology \& Society, 20(1), 123-133.

Fitori, Hisham Salem Omer. (2019). Liverpool John Moores University (United Kingdom). ProQuest Dissertations Publishing, 28329022

Huang, L. L., \& Lin, C. C. (2011). EFL Learners' reading on mobile phones. The JALT CALL Journal, 7(1), 61-78.

Kang, J. (2014). More-than-voice use mobile at the bottom of the pyramid: Analysis of motivational and contextual drivers to mobile use among low income users in South Asia. ProQuest Dissertations and Theses.

Kessler, G. (2010). Fluency and anxiety in self-access speaking tasks: the influence of environment. Computer Assisted Language Learning, 23(4), 361-375. https://doi.org/10.1080/09588221.2010.512551

Larsen-Freeman, D. (2015). Research into practice: Grammar learning and teaching. Language Teaching, 48(02), 263-280. https://doi.org/10.1017/S0261444814000408

Lo, M. L. (2012). Variation Theory and the Improvement of Teaching and Learning. Gothenburg Studies in Educational Sciences 323. Goteborgs Universitet. https://doi.org/10.1007/s35834-013-0078-0

Ma, Z. H., Hwang, W. Y., Chen, S. Y., \& Ding, W. J. (2012). Digital game-based after-school-assisted learning system in English. IEEE, (Ispacs), 130-135. https://doi.org/10.1109/ISPACS.2012.6473466

Mcquillan, J. (2006). iPod in Education: The Potential for Language Acquisition. Language Acquisition, (January). 
Nah, K.-C. (2011). Optimising the use of wireless application protocol (WAP) sites for listening activities in a Korean English as a foreign language (EFL) context. Computer Assisted Language Learning, 24(2), 103-116. https://doi.org/10.1080/09588221.2010.526946

Nikolopoulou, K. (2020). Secondary education teachers' perceptions of mobile phone and tablet use in classrooms: benefits, constraints and concerns. Journal of Computers in Education, 7(2), 257-275

Rozina, A. G., Tengku Nazatul Shima, T. P., Mohamed Ismail, A. S., Rahmah, L. Y., \& Hafiza, A. (2017). Mobile Assisted Language Learning (MALL) In Developing Second Language Learners' understanding of grammar. Journal of Academia UiTM Negeri Sembilan, 5, 187-208.

Song, Y., \& Fox, R. (2008). Using PDA for undergraduate student incidental vocabulary testing. ReCALL, 20(03), 290-314. https://doi.org/10.1017/S0958344008000438 Stockwell, G. (2007). Vocabulary on the move: Investigating an intelligent mobile phone-based vocabulary tutor. Computer Assisted Language Learning, 20(4), 365-383.

Thomas, K., \& Munoz, M. A. (2016). Hold the Phone! High School Students' Perceptions of Mobile Phone Integration in the Classroom. American Secondary Education, 44(3), 2016

Wu, C. J., Chen, G. D., \& Huang, C. W. (2014). Using digital board games for genuine communication in EFL classrooms. Educational Technology Research and Development, 62(2), 209-226. https://doi.org/10.1007/s11423-013-9329-y

Yeh, J. Y. (2014). Mapping the Intellectual Structure of Mobile Commerce. IEEE Xplore, 430-433.

Yen, L., Chen, C. M., \& Huang, H. Bin. (2016). Effects of mobile game-based English vocabulary learning app on learners' perceptions and learning performance: A case study of Taiwanese EFL learners. ProQuest Dissertations and Theses, 255-262. Retrieved from http://www.scopus.com/inward/record.url?eid=2-s2.084979200783\&partnerID=tZOtx3y1

Zaki, A. A., \& Yunus, M. M. (2015). Potential of Mobile Learning in Teaching of ESL Academic Writing. English Language Teaching, 8(6), 11. https://doi.org/10.5539/elt.v8n6p11

Zamani-Miandashti, N., \& Ataei, P. (2015). College students' perceptions of short message service-supported collaborative learning. Innovations in Education and Teaching International, 52(4), 426-436. https://doi.org/10.1080/14703297.2014.900453

Zou, B., \& Li, J. (2015). Exploring mobile apps for English language teaching and learning. Eurocall, 564-568. https://doi.org/10.14705/rpnet.2015.000394 